TITLE:

\title{
Elastic wave validation of large concrete structures repaired by means of cement grouting
}

AUTHOR(S):

Shiotani, T.; Momoki, S.; Chai, H.; Aggelis, D.G.

\section{CITATION:}

Shiotani, T.... [et al]. Elastic wave validation of large concrete structures repaired by means of cement grouting. Construction and Building Materials 2009, 23(7): 2647-2652

\section{ISSUE DATE:}

2009-07

URL:

http://hdl.handle.net/2433/123384

\section{RIGHT:}

Copyright (c) 2009 Elsevier; This is not the published version. Please cite only the published version.; この論文は出版社版でありません。引用の 際には出版社版をご確認ご利用ください。 


\title{
Elastic wave validation of large concrete structures repaired by means of cement
}

\section{grouting}

\author{
T. Shiotani ${ }^{\text {a }}$, S. Momoki ${ }^{\text {b }}$ H. Chai ${ }^{\text {b }}$ D. G. Aggelis ${ }^{\text {c* }}$ \\ ${ }^{a}$ Graduate School of Engineering, Kyoto University, C1-2-236, Kyoto-Daigaku-Katsura, Nishikyo- \\ Ku, Kyoto 615-8540, Japan \\ ${ }^{b}$ Research Institute of Technology, Tobishima Corporation, 5472 Kimagase, Noda, Chiba 270-0222, \\ Japan \\ ${ }^{c}$ Department of Materials Science and Engineering, University of Ioannina, Ioannina 45110, Greece
}

\begin{abstract}
Injection of repair agent (grout) into boreholes is a repair technique commonly applied to deteriorated concrete structures, ensuring that interconnected cracks and voids are eliminated. The repair effect is evaluated from the increase in the pulse velocity between before and after grouting. Measured velocities after grouting, however, unexpectedly led to a remarkable decrease in the case of a 70-year old dam. This resulted in a doubt about the efficiency of repair. Through investigation, it was concluded that the velocity decrease was attributed to the initial low stiffness of the cement grouting agent due to insufficient hydration in cold environments where the structure is located. Theoretical investigation based on multiple scattering theory is performed, as the filling material acts as a scatterer in the concrete matrix. It is found that the pulse velocity of the structure is lower than that of the initial damaged condition before the repair agent becomes hardened up to an adequate level of stiffness. Accordingly, the amount of the agent injected into the structure was strongly correlated with the velocity decrease after grouting. As a result, the velocity decrease was observed in the repaired dam. Further validation was conducted after a period of two years in the same structure with exactly the same sensor arrangement as before. It is clarified that, the velocity distribution measured is in remarkable agreement with that predicted in the theory just after grouting.
\end{abstract}

Keywords: Concrete, elastic waves, grouting, repair evaluation, pulse velocity, scattering.

*Corresponding author: Tel: +30 26510 98006, Fax: +30 26510 98054, daggelis@cc.uoi.gr 


\section{Introduction}

Since the number of aging concrete structures has been continuously increasing worldwide, effective damage assessment as well as repairing techniques are in high demand [1-3]. The velocities of elastic waves (pulse velocity or P-wave velocity) are a widely accepted parameter correlated with the structural condition of concrete [4,5]. In case that non-destructive testing (NDT) by the pulse velocity measurements is applied before and after the repair, the discrepancy between the measured values should reflect the improvement due to repair.

A case discussed here is a deteriorated large pier in a concrete dam. P-wave velocities were measured to estimate the internal condition at several cross sections. Then, the pier was repaired by grouting after drilling boreholes from the surface. At two weeks elapsed after grouting, P-wave velocities were measured at the same locations as before. Surprisingly they revealed substantial reduction of the velocities despite that the voids were filled with grouting. The fact made estimation of repair effectiveness troublesome. Even if the grouting material is still fresh and soft, P-wave velocities of the structure were expected to be increased. From the mechanical point of view, the elastic stiffness at a cross section of the structure should be increased, because interconnected cracks and voids must be filled with a grouting material. Unfortunately, this improvement might not readily reflect in terms of the propagating velocity, making the estimation confusing for the engineers. A similar result concerning decreased velocities after grouting was previously reported [6], without a proper explanation.

A careful study is conducted to examine the scattering interaction of elastic waves in the case of fresh and un-hydrated grout. Important parameters are the elastic moduli of the concrete matrix and of the grouted material at different ages as well as the temperature which affects the development of 
the elastic modulus. The analysis is based on the multiple scattering theory [7] and is applied not only to verify the initial velocity decrease but also to estimate the velocity distribution with hardened grout.

This paper deals with results of velocity measurement and the prediction of the velocity distribution at the hardened state. Details about the repair program and other investigation of the dam piers, including acoustic emission results, are found elsewhere [8,9].

\section{P-wave velocity measurement}

Measurements of P-wave velocities were conducted at several cross sections of the concrete pier. Fifteen piezoelectric accelerometers of flat response up to $30 \mathrm{kHz}$ (SAF51, Fuji Ceramics Corp.) were placed in a straight line at intervals of $0.5 \mathrm{~m}$ along one side of a $7 \mathrm{~m} \mathrm{x} 4.1 \mathrm{~m}$ section in Fig. 1 . The impact was driven consecutively at several heights, while an accelerometer was set adjacent to the impact hammer to record each impact and trigger the acquisition of the other 15 receivers attached to the opposite side. As a result, 225 wave paths were examined and afterwards the impact was driven from the opposite side in order to double the data. The signals were recorded by a 16channel TEAC CX-1 system at a sampling frequency of $200 \mathrm{kHz}$.

Based on the time-of-flights measured at all wave paths, a tomogram of the specific cross-section was created. In Fig. 2a a tomogram of one section in the pier is shown. The velocities are denoted in units of $\mathrm{m} / \mathrm{s}$ on the right. The horizontal and vertical axes show the dimensions of pier section in meters. Pulse velocity in the lattice (each cell is of dimensions $0.5 \mathrm{~m} \times 0.5 \mathrm{~m}$ ) is calculated with a specialized software [10]. According to empirical relationships with mechanical properties, 
velocities above $3500 \mathrm{~m} / \mathrm{s}$ indicate sound concrete, while these lower than $3500 \mathrm{~m} / \mathrm{s}$ suggest poor quality [4]. Thus the overall condition of the section before repair is found to be satisfactory since all velocities are around $3600 \mathrm{~m} / \mathrm{s}$, with a standard deviation of $10 \%$. The light-yellow zones, corresponding to velocities lower than $3500 \mathrm{~m} / \mathrm{s}$, can be seen mainly along the sides. By drilling core samples at the side, the areas were confirmed to be of low quality. Although the general condition was satisfactory, in order to improve the low quality areas and extend the service life until the next monitoring, a repair program was designed including grouting by boreholes drilled on the surfaces in horizontal and vertical direction.

In Fig. $2 \mathrm{~b}$ the tomogram of the same section two weeks after grout injection is depicted. It is obvious that the values of the velocity distribution are much lower than those in Fig. 2a, particularly in central areas (around $2500 \mathrm{~m} / \mathrm{s}$ ). Even if the grouting performance for cracks was incomplete, a negative effect on the velocity distribution was not expected.

\section{Wave Scattering}

Concrete is by definition an inhomogeneous material, containing aggregates, as well as voids and cracks. Therefore, scattering should be taken into account in wave propagation through concrete. Inhomogeneities interact with the waves, as peculiar cases have been reported [11-13]. Thus, the velocity decrease in a matrix might happen although it is "reinforced" by grouting. Scattering theory has been extensively studied in order to explain wave propagation in ultrasonics [7,14-17]. The goal is to derive the velocity distribution in an equivalent dispersive medium, which contains the individual constituents as modeled in Fig. 3. Due to random orientation of actual cracks, the spherical shape is considered and applied to model an inhomogeneous medium [15-17]. 
When a longitudinal wave impinges on a spherical scatterer, the energy is redistributed to any possible directions. The distribution is governed by the "scattering coefficients" $A_{n}$, which are the solutions of the continuity equations on the interface between the scatterer and the matrix [18]. The continuity equations, which concern radial and circumferential stresses and displacements, can be solved analytically. Four lengthy equations are formulated in the literature, e.g. $[13,19]$. Although they are not presented here, it is mentioned that the resulting coefficients $A_{n}$ are governed by the size of the scatterer relative to the propagating wavelength, as well as the wave velocity of the scatterer relative to the velocity of the matrix.

After derivation of the scattering coefficients, the complex forward and backward scattering amplitudes, $f(0)$ and $f(\pi)$, can be calculated. These represent the displacement amplitudes of the waves that continue to travel in the direction of the incident, and of the reflected [18]:

$$
\begin{aligned}
& f(0)=\frac{1}{j k_{C}} \sum_{n=0}^{\infty}(2 n+1) A_{n} \\
& f(\pi)=\frac{1}{j k_{C}} \sum_{n=0}^{\infty}(-1)^{n}(2 n+1) A_{n}
\end{aligned}
$$

where $j$ is the imaginary number and $k_{C}$ is the wavenumber of the matrix (angular frequency divided by wave velocity). The total number of terms considered, $n$, defines the accuracy of the calculation. It has been shown that $n$ should be equal to $k_{C} \cdot a$, where $a$ the size of the scatterer [13].

Dealing with the corresponding problem with a group of scatterers, the mechanical properties of the constituents (matrix and scatterers) are combined in the "dispersion relation" to yield the complex wavenumber $k$ of the effective and composite medium [7, 14]: 
$\left(\frac{k}{k_{c}}\right)^{2}=1+\frac{3}{k_{c}{ }^{2}} \sum_{i} \frac{\varphi_{i} f_{i}(0)}{R_{i}{ }^{3}}+\frac{9}{4 k_{c}{ }^{4}} \sum_{i} \frac{\varphi_{i}{ }^{6}}{R_{i}{ }^{6}}\left[f_{i}^{2}(0)-f_{i}^{2}(\pi)\right]$

where $\varphi$ is the volume concentration and $R$ the radius of the scatterers,

The subscript $i$ denotes different populations of scatterers. Here the values 1 and 2 are assigned to aggregates and cavities.

Then, phase velocity $C(\omega)$ and attenuation $\alpha(\omega)$ of the composite medium are calculated from $[13,16,19]:$

$k(\omega)=\frac{\omega}{C(\omega)}+j \cdot \alpha(\omega)$

where $\omega$ is the angular frequency.

Thus, the phase velocity, $C(\omega)$ is calculated from the real part of the effective wavenumber $k(\omega)$ at angular frequency $\omega$, while the imaginary part of $k(\omega)$ corresponds to the attenuation coefficient $\alpha(\omega)$.

\section{Model parameters}

In order to theoretically calculate the wave velocity of concrete at different ages of the grouting material, such three cases were considered as i) concrete with voids before repair, ii) concrete with soft grout of 2 weeks elapsed and iii) concrete with fully hardened grout, i.e., two years after the grouting. 
For the case of concrete with cavities, necessary parameters are the elastic properties and density of the concrete matrix. The density was measured from core samples as the average of $2300 \mathrm{~kg} / \mathrm{m}^{3}$. The ultrasonic test of the same cores resulted in the average velocity of approximately $4000 \mathrm{~m} / \mathrm{s}$. Assuming a Poisson's ratio of 0.2 , the modulus of elasticity of the pier concrete is estimated as 35 GPa, as seen in Table 1.

In the second case, the cavities of concrete are filled with soft and fresh grout ( 2 weeks old) and in the third case they are filled with hardened grout ( 2 years old). The modulus of elasticity, E, of the grout, Poisson's ratio, $v$, and density $\rho$, for the numerical model, are presented in Table 1 as "scatterer 1". These parameters were obtained by ultrasonic experiments on specimens of the same materials as used in repair work at the site for the corresponding ages of grout [20] and applied to the models. Concerning these laboratory measurements, it is noted that grouting materials were maintained in an environmental chamber at the temperature of $5{ }^{\circ} \mathrm{C}$, as similar to the average surface temperature at the site, which was maintained by jet heaters, as specified in [21].

As shown in the model of Fig. 3, except the voids which act as scatterers, the matrix also contains aggregates which are taken into account as "scatterers 2" given in Table 1.

Due to the impact hammer, the frequencies of the test were below $20 \mathrm{kHz}$ and the numerical analysis was conducted at the representative frequency of $10 \mathrm{kHz}$. The wavelength corresponds to approximately $40 \mathrm{~cm}$, which is longer than the sizes of inhomogeneity in concrete (voids and aggregate). 


\section{Numerical results}

The velocities calculated at the different ages can be seen in Fig. 4. If $15 \%$ volume concentration of the scatterer (void) is assumed, the velocity of concrete is $4313 \mathrm{~m} / \mathrm{s}$. When the voids are filled with soft grout of 2 weeks-age, concrete exhibits lower velocity than that before repair, as $3864 \mathrm{~m} / \mathrm{s}$, reduced by $\delta \mathrm{V}_{\mathrm{i} 15 \%}$. Therefore, it is theoretically verified that the velocity of a freshly grouted structure does not necessarily increase. Using the properties of hardened grout, corresponding to two years after repair, a final increase $\delta \mathrm{V}_{\mathrm{f} 15 \%}$ in the velocity to $4445 \mathrm{~m} / \mathrm{s}$ is predicted. The case of $1 \%$ volume concentration is also shown in Fig. 4. It is found that the discrepancies $\delta \mathrm{V}_{\mathrm{i} 1 \%}$ and $\delta \mathrm{V}_{\mathrm{fl} \%}$ are quite small although the similar trend is observed. This implies that the volume concentration of the scatterer is important for scattering interactions.

Varying the volume concentration from $1 \%$ to $15 \%$, for the initial (concrete with voids), the second (freshly grouted) and the third (hardened grout) cases were solved. Results are shown in Fig. 5a and b. Fig. 5a shows the correlation between the initial velocity decrease, $\delta V_{i}$ and the volume concentration of voids. As seen, the volume of voids is strongly correlated to the velocity decrease. The consecutive final velocity increase $\delta \mathrm{V}_{\mathrm{f}}$ (between two weeks and two years after repair), was calculated and shown in Fig. 5 b.

Based on the relation in Fig. 5a, the measured velocity decrease can lead to the estimation of the volume concentration of voids. The void concentration information is useful. However, as stated earlier, the estimation of the repair efficiency is conducted by the pulse velocity value. This is the reason why theoretical results are again produced using this void concentration and the final elastic constants of the grouting material resulting in the curves of Fig. $5 b$. 
The practical importance of such a rule is related to the tomography results. According to the tomography procedure, the cross section under examination is divided into a number of cells, as seen in Fig. 2. Combining the total number of measured paths, a characteristic value of velocity is calculated for each cell [22]. As an example, for the upper left cell in Fig. 2a, velocity is $3614 \mathrm{~m} / \mathrm{s}$ (before repair) and $2949 \mathrm{~m} / \mathrm{s}$ after repair (Fig. 2b). The decrease is $665 \mathrm{~m} / \mathrm{s}$ and, according to the present analysis, leads to the void volume concentration of $22 \%$, as seen by the arrows in Fig. $5 \mathrm{a}$. Consecutively, this void concentration results in a final increase of $880 \mathrm{~m} / \mathrm{s}$, as seen in Fig. $5 \mathrm{~b}$, so that the final velocity of the specific cell is predicted to $3829 \mathrm{~m} / \mathrm{s}(2949 \mathrm{~m} / \mathrm{s}+880 \mathrm{~m} / \mathrm{s})$. This procedure is repeated for the total number of cells and the predicted tomogram is constructed (Fig. 2c). Additionally, the calculated void concentration for the whole cross section can be seen in Fig. 6 .

It is seen that the final velocity in almost the whole cross-section is expected to smoothly increase after hardening of grout, something that is not evident from the first few weeks after repair (see Fig. 2b). Specifically, the average velocity calculated for the total number of cells before repair was 3604 m/s (Fig. 2a) and the final velocity was predicted as $3760 \mathrm{~m} / \mathrm{s}$ (Fig. 2c). In the meantime the average velocity decreased to $3107 \mathrm{~m} / \mathrm{s}$.

\section{Validation}

\subsection{Correlation with actual grout amount}

In this repair work, the amount of grouted volume into each borehole at every $1 \mathrm{~m}$ in height was known. In Fig. 7, the amount of grouted mass normalized by the maximum value of $242 \mathrm{~kg}$ along the distance from the top of the pier is depicted. In the same figure, the velocity difference before and 
after grouting, $\delta \mathrm{V}_{\mathrm{i}}$, normalized by the maximum, is also plotted. It is seen that at the positions with large velocity decrease (e.g. $9 \mathrm{~m}$ ), a great amount of grout had been actually injected. On the contrary, at locations with smaller velocity difference the grouted volumes were small (e.g., height of $10 \mathrm{~m}$ ). Specifically at $9 \mathrm{~m}$ from the top, the velocity before grouting was measured as $4008 \mathrm{~m} / \mathrm{s}$, while two weeks after grouting it was measured as $3124 \mathrm{~m} / \mathrm{s}$. This difference of $884 \mathrm{~m} / \mathrm{s}$ corresponds to the maximum injected mass of $242 \mathrm{~kg}$ at the region. On the other hand, at the depths of smaller velocity differences (about $200 \mathrm{~m} / \mathrm{s}$ ), the grouted mass was also smaller, around $40-80 \mathrm{~kg}$, supporting strongly the argument that the velocity decrease resulted from the presence of the newly injected soft material. Thus, it is confirmed that the velocity difference follows the mass of grout injected into each borehole.

Experimental studies on porous concrete have also supported these findings $[20,23,24]$. The velocity decrease resulted immediately after the grout injection, and could be more obvious under lower curing temperature.

\subsection{Validation measurement after two years}

It would be desirable to confirm the above statements in real conditions, i.e., the same structure after a period of time allowing completion of the grout hardening process. This is not always possible due to logistics and service of the structure as well as, of course, the additional monitoring cost. However for this specific case, two years after the injection, the pier was again tested to actually confirm if the pulse velocities were finally increased according to the above analysis and estimation. The results are shown in Table 2 for the different ages and positions measured. In all of them an initial decrease was exhibited (two weeks after repair). The velocity measured after two years on exactly the same 
lines, as well as the predicted values are denoted in the next columns. The error between the actual and predicted values (absolute difference normalized by the measured) averages less than 3.5\%. The best agreement is found in paths \#3 and \#4. In path \#3 the initial velocity decrease was only $23 \mathrm{~m} / \mathrm{s}$ from $4316 \mathrm{~m} / \mathrm{s}$ to $4293 \mathrm{~m} / \mathrm{s}$. Scattering theory predicted a slight final increase to $4319 \mathrm{~m} / \mathrm{s}$ which was remarkably close to the measured $4320 \mathrm{~m} / \mathrm{s}$ two years later. On the other hand, in path $\# 4$, a severe decrease about $1000 \mathrm{~m} / \mathrm{s}$ was observed after repair. The final increase to $4411 \mathrm{~m} / \mathrm{s}$ is predicted by the theory. The measured velocity after two years was $4348 \mathrm{~m} / \mathrm{s}$, showing just $1.5 \%$ lower. As aforementioned, the errors between predicted and measured velocities after 2 years are $3.44 \%$ in average. The proposed procedure with scattering theory seems reasonable and practical in order to estimate the repair effectiveness with P-wave velocity even during the hydration process of the cementitious materials.

\section{Discussion of limitations}

The predictions made by the above methodology are based on the elasticity values used as input in the scattering model. Thus, it is of paramount importance to measure cores of the healthy part of the structure, as well as the same grouting material at an early age after repair (in our case two weeks) and at very old age (assuming no further hardening development of grout). The temperature conditions of the grout should be similar to the actual conditions at site in order to follow the same hardening development and yield suitable elasticity values. If the above conditions are not fulfilled for each different structure, the accuracy could be reduced, since different correlation curves between void volume content and velocity discrepancies will apply. 
A parameter that requires further attention is the modeling of inhomogeneities. Although spherical shape is considered adequate for general use due to random orientation of cracks and aggregates, other shapes as ellipsoidal could resemble closer the actual situation in concrete. Another question concerns the percentage of filling of cracks with grout. In the present work, complete filling into the cracks was assumed when modeling. In case that partial filling actually takes place, both grout scatterers and void scatterers would behave simultaneously, making velocity discrepancies lower.

\section{Conclusions}

The main contribution of this work hopefully lies in the field of monitoring of repaired structures' performance, which is a demanding task: to confirm the repair effectiveness and to establish the following repair program as well. Quantitative assessment of repair work is performed by means of the velocity distribution of P-waves. Elastic wave scattering theory is used to explain the initial decrease of pulse velocity after grout injection. The reason for the decrease is the initially low mechanical properties of fresh grout. Theory is also used to predict the pulse velocity of the structure after the final hydration of grout which is remarkably close to the velocities measured two years later. A more sensitive analysis could be undertaken in case that a high voltage, high frequency excitation technique is applied in the site. Also, since wave attenuation is considered more sensitive to inhomogeneities, attenuation tomography could prove more efficient for such a characterization. Elastic wave examination has been long used for estimation of concretes' structural integrity. Pulse velocity measurements aided by scattering theory, in laboratory and in-situ, are expected to greatly enhance NDT capabilities. 


\section{References}

[1] Colombo S, Forde MC, Main IG, Shigeishi M. Predicting the ultimate bending capacity of concrete beams from the "relaxation ratio" analysis of AE signals. Construction and Building Materials 2005;19:746-754.

[2] Shiotani T, Aggelis DG, Makishima O. Global monitoring of concrete bridge using acoustic emission, Journal of Acoustic Emission 2007;25:308-315.

[3] Ohtsu M, Isoda T, Tomoda Y. Acoustic emission techniques standardized for concrete structures, Journal of Acoustic Emission 2007;25:21-32.

[4] Malhotra VM, Carino NJ, (Eds.). CRC Handbook on Nondestructive Testing of Concrete, CRC Press, Florida, 1991.

[5] Popovics S. Analysis of the Concrete Strength versus Ultrasonic Pulse Velocity Relationship, Materials Evaluation 2001;59(2):123-129.

[6] Kase EJ, Ross TA. Quality assurance of deep foundation elements, Florida department of transportation, 3rd International conference on Applied Geophysics - Geophysics 2003, December 8-12, Orlando, Florida, 2003

[7] Foldy LL. The multiple scattering of waves, Phys. Rev. 1945;67:107-119.

[8] Shiotani T, Aggelis DG. Evaluation of repair effect for deteriorated concrete piers of intake dam using AE activity, Journal of Acoustic Emission, 2007;25:69-79.

[9] Shiotani T, Aggelis DG. Damage quantification of aging concrete structures by means of NDT, Structural Faults and Repair 2006, June 13-15 2006, Edinburgh (in CD).

[10] Kobayashi Y, ShiotaniT, Aggelis DG, Shiojiri H. Three-dimensional seismic tomography for existing concrete structures, Proceedings of the Second International Operational Modal Analysis Conference, IOMAC 2007, April 30-May 2, 2007, Copenhagen, Vol. 2 pp. 595-600

[11] Kaelin B, Johnson LR. Dynamic composite elastic medium theory. Part II. Three-dimensional media, J. Appl. Phys. 1998;84:5458-5468.

[12] Anson LW, Chivers RC. Utrasonic velocity in suspensions of solids in solids - a comparison of 
theory and experiment, J. Phys. D, 1993;26:1566-1575.

[13] Aggelis DG, Tsinopoulos SV, Polyzos D. An iterative effective medium approximation (IEMA) for wave dispersion and attenuation predictions in particulate composites, suspensions and emulsions. Journal of the Acoustical Society of America 2004;116:3443-3452.

[14] Waterman PC, Truell R. Multiple scattering of waves, J. Math. Phys. 1961;2:512-537.

[15] Punurai W, Jarzynski J, Qu J, Kurtis KE, Jacobs LJ. Characterization of entrained air voids in cement paste with scattered ultrasound, NDT\&E INT 2006;39(6):514-524.

[16] Chaix JF, Garnier V, Corneloup G. Ultrasonic wave propagation in heterogeneous solid media: Theoretical analysis and experimental validation, Ultrasonics 2006;44:200-210.

[17] Aggelis DG, Polyzos D, Philippidis TP. Wave dispersion and attenuation in fresh mortar: theoretical predictions vs. experimental results, Journal of the Mechanics and Physics of Solids 2005;53:857-883.

[18] Ying CF, Truell R. Scattering of a plane longitudinal wave by a spherical obstacle in an isotropically elastic solid, Journal of Applied Physics 1956;27(9):1086-1097.

[19] Challis RE, Tebbutt JS, Holmes AK. Equivalence between three scattering formulations for ultrasonic propagation in particulate mixtures, J Phys D: Appl Phys 1998;31:3481-3497.

[20] Aggelis DG, Shiotani T. An Experimental Study of Wave Propagation through Hydrating Grout and Grouted Concrete, ACI Materials J, accepted 2008.

[21] JSCE Guidelines for Concrete. No.6, Standard Specification for Concrete Structures, "Materials and Construction", 2002;pp. 443.

[22] Sassa K. Suggested methods for seismic testing within and between boreholes, International Journal of Rock Mechanics and Mining Science \& Geomechanics Abstracts 1988;25(6):449-472.

[23] Aggelis DG, Shiotani T. Damage evaluation on concrete materials using characteristics of elastic waves, Structural Faults and Repair 2006, June 13-15 2006, Edinburgh (in CD).

[24] Aggelis DG, Shiotani T. Damage characterization of deteriorated concrete structures by stress wave methods. Emerging Technologies in NDT, (ETNDT 4), April 2-4, 2007, Stuttgart, Germany. 
Table 1. Material properties of numerical model

\begin{tabular}{|c|c|c|}
\hline \multicolumn{3}{|c|}{ Matrix (concrete) } \\
\hline $\mathrm{E}(\mathrm{GPa})$ & \multicolumn{2}{|c|}{35} \\
\hline $\mathrm{V}$ & \multicolumn{2}{|c|}{0.2} \\
\hline$\rho\left(\mathrm{kg} / \mathrm{m}^{3}\right)$ & \multicolumn{2}{|c|}{2300} \\
\hline \multicolumn{3}{|c|}{ Scatterer 1 (voids, before repair) } \\
\hline $\mathrm{r}(\mathrm{mm})$ & \multicolumn{2}{|c|}{5} \\
\hline$\varphi(\%)$ & \multicolumn{2}{|c|}{$1,3,5,10,15$} \\
\hline \multicolumn{3}{|c|}{ Scatterer 1 (grout, after repair) } \\
\hline & 2 weeks & 2 year \\
\hline $\mathrm{E}(\mathrm{GPa})$ & 12.8 & 21.5 \\
\hline $\mathrm{v}$ & 0.30 & 0.20 \\
\hline$\rho\left(\mathrm{kg} / \mathrm{m}^{3}\right)$ & \multicolumn{2}{|c|}{1498} \\
\hline$\varphi(\%)$ & \multicolumn{2}{|c|}{$1,3,5,10,15$} \\
\hline \multicolumn{3}{|c|}{ Scatterer 2 (aggregate) } \\
\hline $\mathrm{E}(\mathrm{GPa})$ & \multicolumn{2}{|c|}{$80 \mathrm{GPa}$} \\
\hline $\mathrm{v}$ & \multicolumn{2}{|c|}{0.2} \\
\hline $\mathrm{r}(\mathrm{mm})$ & \multicolumn{2}{|c|}{25} \\
\hline$\rho\left(\mathrm{kg} / \mathrm{m}^{3}\right)$ & \multicolumn{2}{|c|}{2650} \\
\hline$\varphi(\%)$ & \multicolumn{2}{|c|}{40} \\
\hline
\end{tabular}

Table 2. Comparison of predicted and measured final velocity $(\mathrm{m} / \mathrm{s})$

$\begin{array}{lccccc}\text { Paths } & \begin{array}{c}\text { Measured } \\ \text { velocity } \\ \text { before repair }\end{array} & \begin{array}{c}\text { Measured } \\ \text { velocity } \\ \text { 2 weeks after } \\ \text { repair }\end{array} & \begin{array}{c}\text { Measured } \\ \text { final velocity } \\ \text { 2 years after } \\ \text { repair }\end{array} & \begin{array}{c}\text { Predicted } \\ \text { final velocity }\end{array} & \begin{array}{c}\text { |Error| } \\ (\%)\end{array} \\ \text { path \#1 } & 4057 & 3661 & 4274 & 4113 & 3.75 \\ \text { path \#2 } & 4018 & 3961 & 4320 & 4026 & 6.81 \\ \text { path \#3 } & 4316 & 4293 & 4320 & 4319 & 0.02 \\ \text { path \#4 } & 4273 & 3293 & 4348 & 4411 & -1.46 \\ \text { path \#5 } & 4096 & 3685 & 4386 & 4154 & 5.29 \\ \text { path \#6 } & 4231 & 3877 & 4405 & 4281 & 2.82 \\ \text { path \#7 } & 4316 & 4100 & 4525 & 4346 & 3.95 \\ \text { Average } & & & & & 3.44\end{array}$


Figure captions

Fig. 1 P-wave measurement setup in a concrete cross-section. (Some of the 450 total paths are suggestively illustrated)

Fig. 2 Tomogram at one section (a) before repair, (b) two weeks after repair and (c) predicted after full hydration of grout.

Fig. 3 Material modeling for scattering in concrete

Fig. 4 Theoretical pulse velocity for different volume concentration of scatterers and age of grout.

Fig. 5 Correlation plot between (a) initial velocity decrease and damage content, and (b) damage content and eventual velocity increase.

Fig. 6 Visualization of void content for the cross section of Fig. 2(a).

Fig. 7 Amount of grouted volume and velocity drop at each height of the pier. 


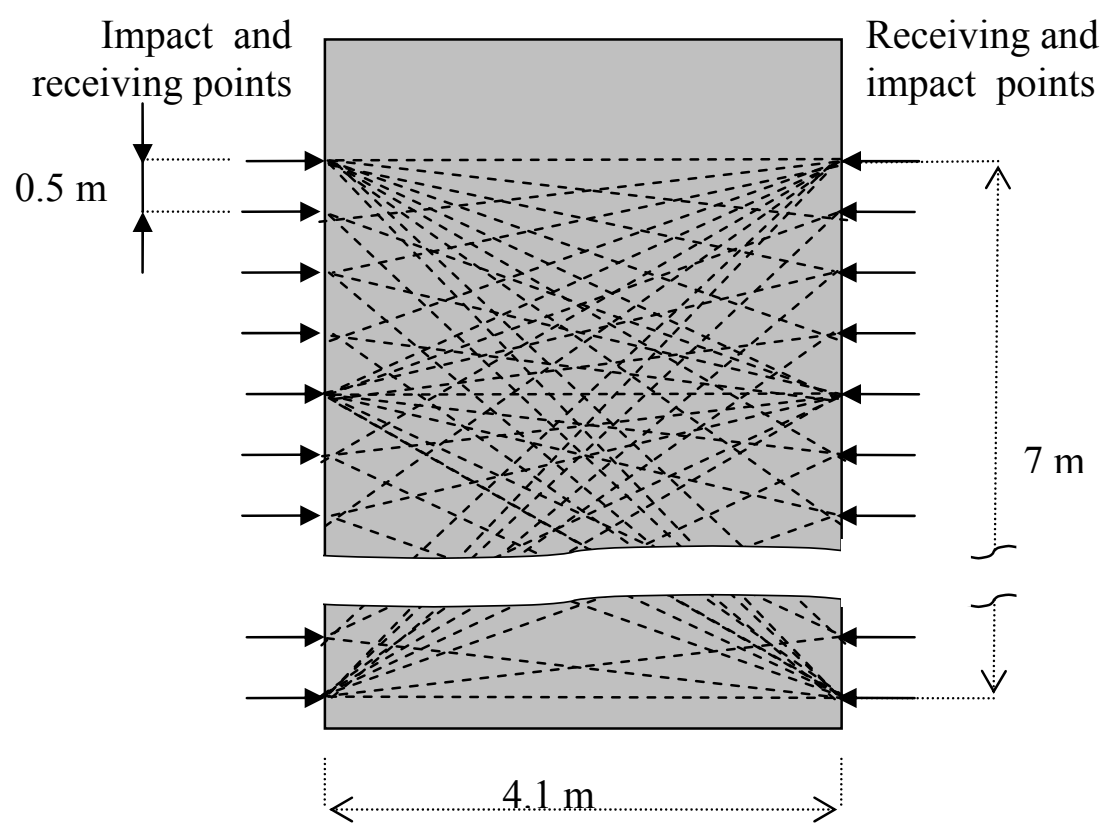

Fig. $1 \mathrm{P}$-wave measurement setup in a concrete cross-section. (Some of the 450 total paths are suggestively illustrated) 
(a)

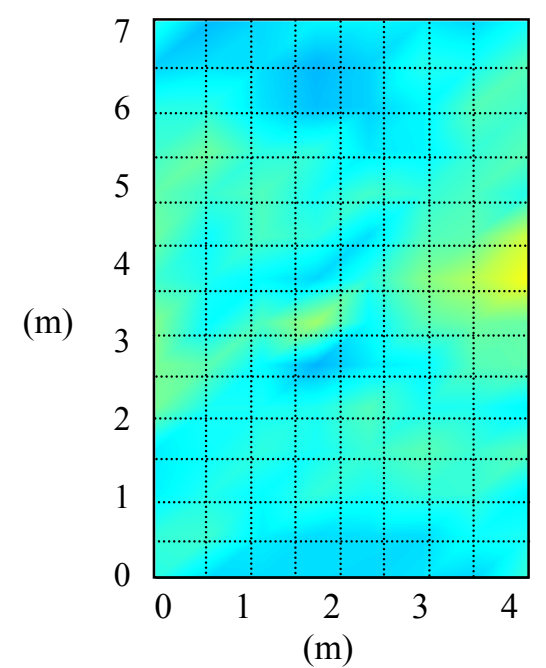

(m) (b)

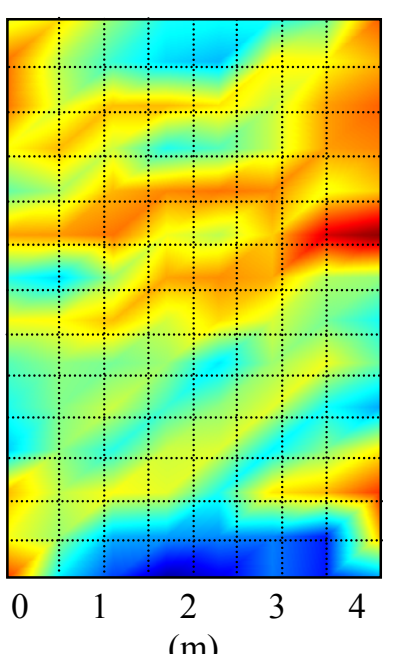

(m) (c)

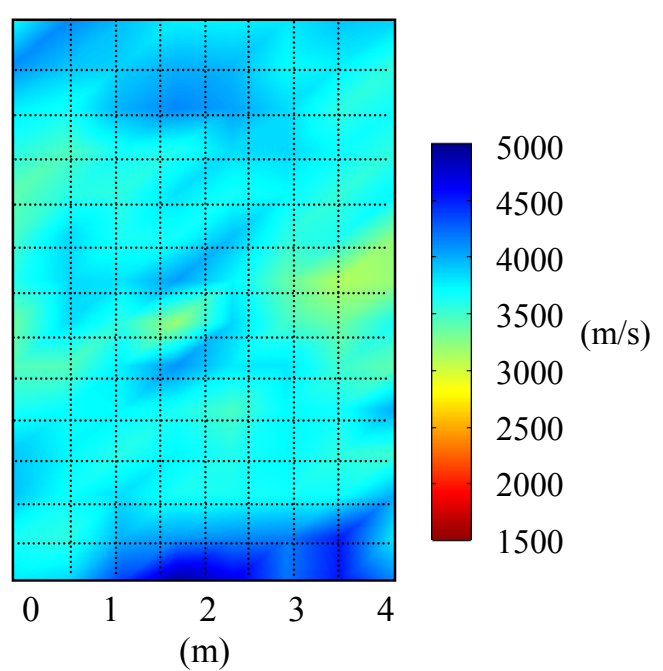

Fig. 2. Tomogram at one section (a) before repair, (b) two weeks after repair and (c) predicted after full hydration of grout. 
Concrete with aggregate and cracks

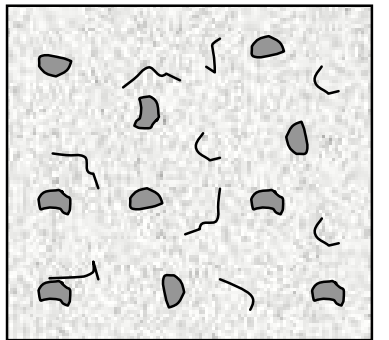

Concrete model with aggregate and voids

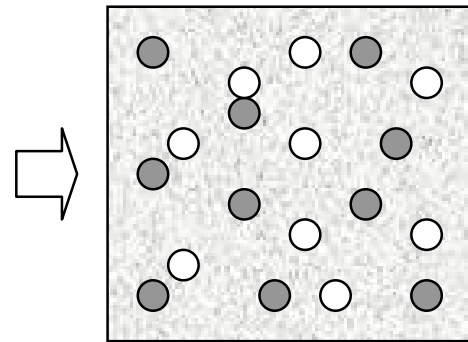

Equivalent homogeneous dispersive material

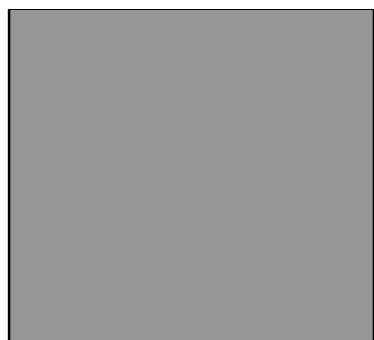

Fig. 3 Material modeling for scattering in concrete 


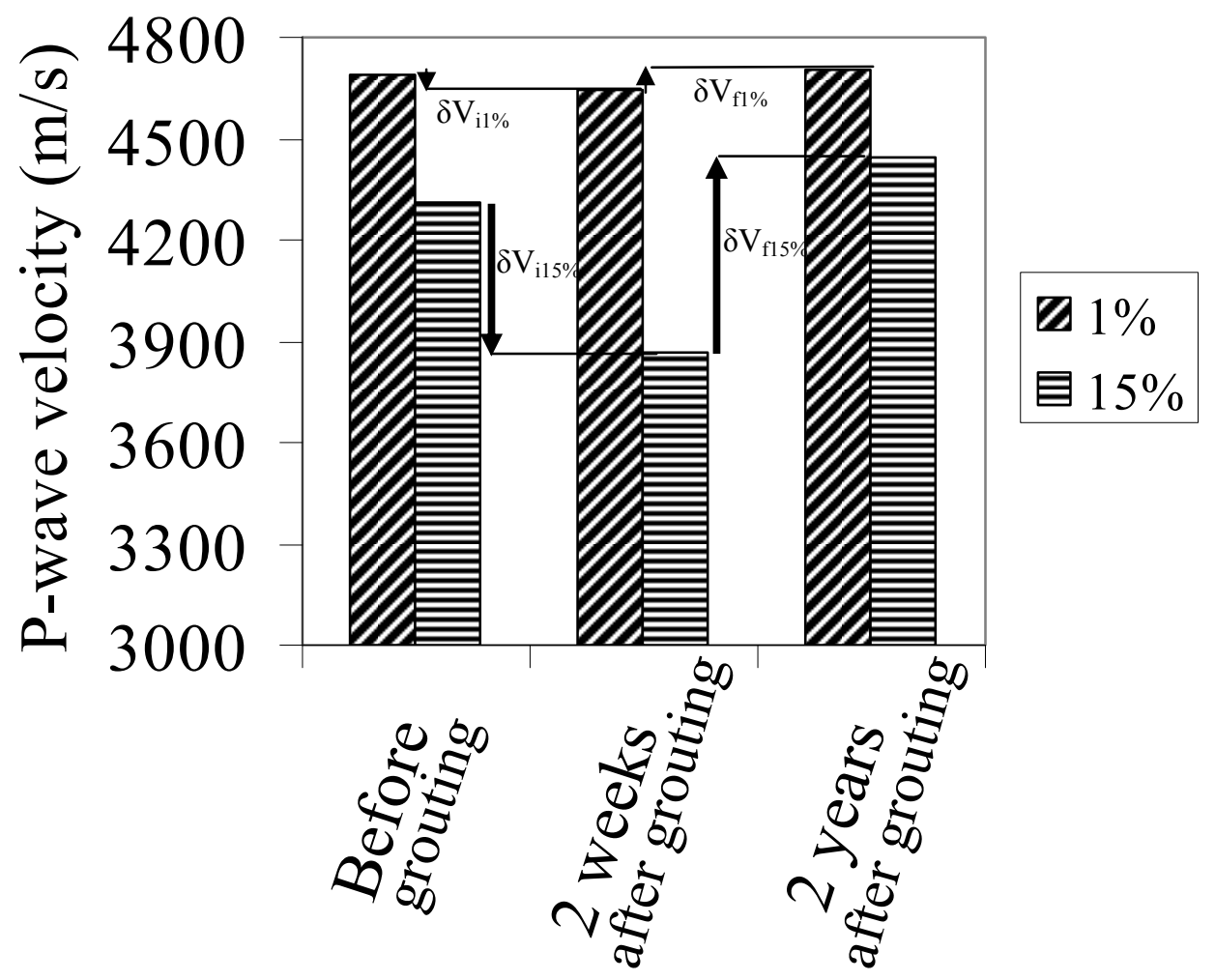

Fig. 4. Theoretical pulse velocity for different volume concentration of scatterers and age of grout. 

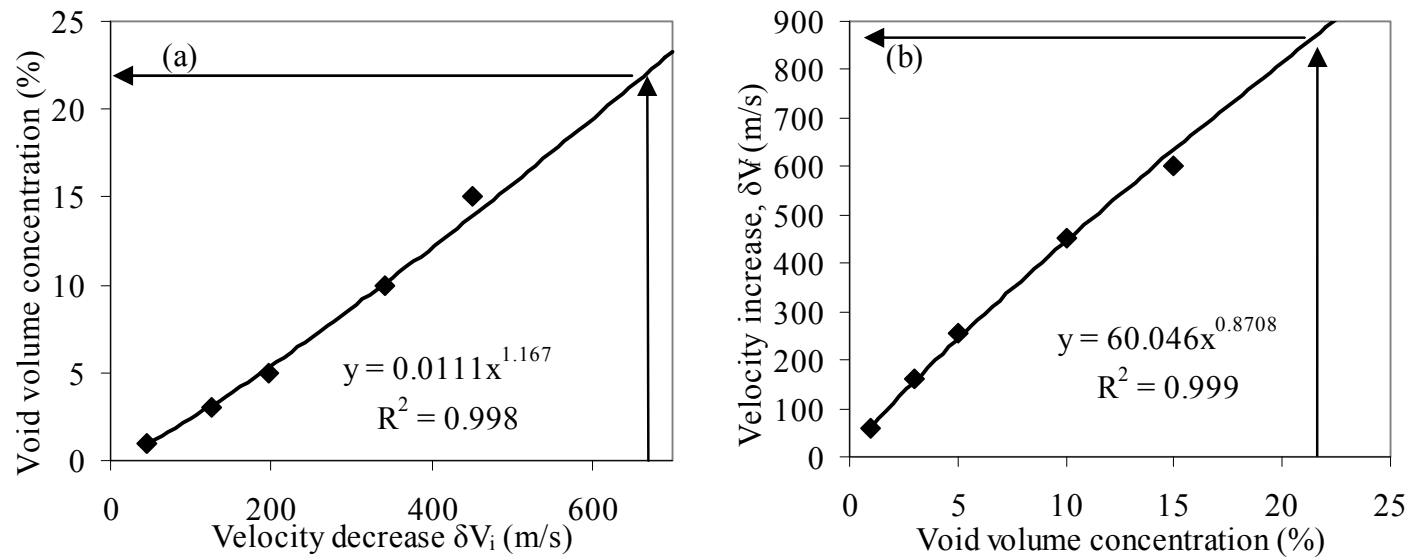

Fig. 5. Correlation plot between (a) initial velocity decrease and damage content, and (b) damage content and eventual velocity increase. 


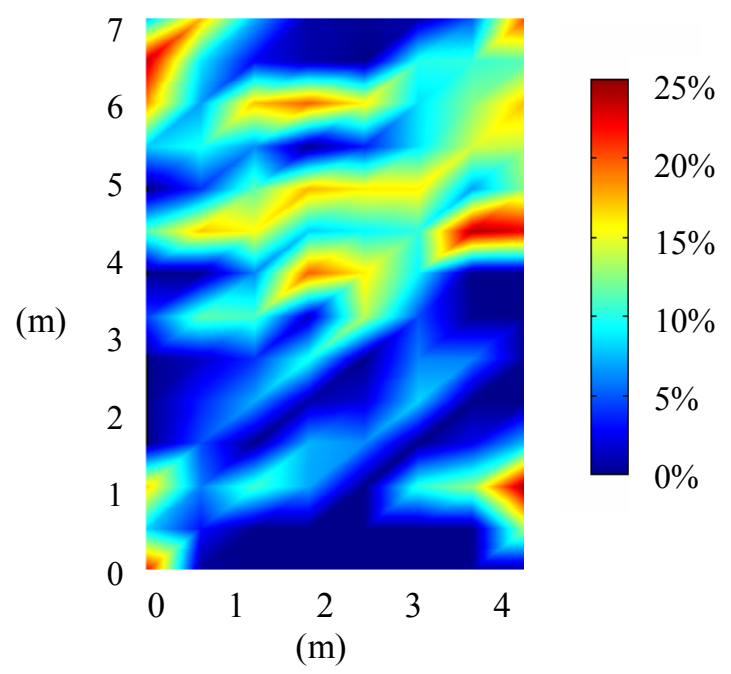

Fig. 6. Visualization of void content for the cross section of Fig. 2(a). 
Normalised to maximum

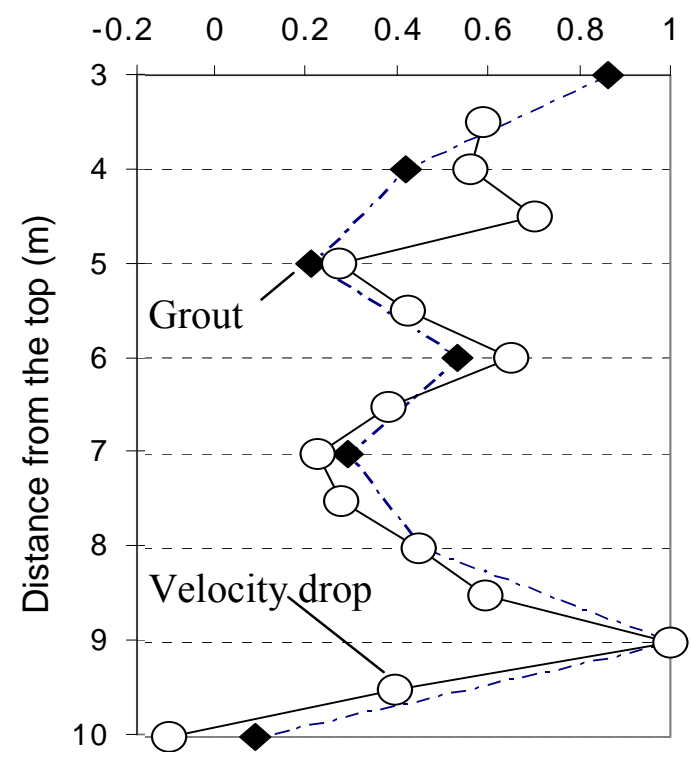

Fig. 7. Amount of grouted volume and velocity drop at each height of the pier. 